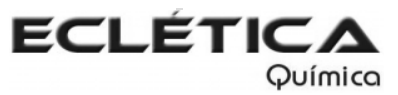

www.scielo.br/eq

Volume 31, número 1, 2006

\title{
Thermal degradation behaviour of some polydithiooxamide metal complexes
}

\author{
H. Al-Maydamal , A. El-Shekeil ${ }^{*}$, M. A. Khalid ${ }^{2}$ and A. Al-Karbouly ${ }^{3}$ \\ ${ }^{\prime}$ Chemistry Department and ${ }^{2}$ Physics Department, Faculty of Science, Sana' a University, P. O. Box 12463, Sana' a, Yemen. \\ ${ }^{3}$ Chemistry Department, Faculty of Science, Anbar University, Khalidiya, Iraq \\ *Corresponding author.E-mail : shekeil@yemen.net.ye
}

\begin{abstract}
The thermal decomposition behavior of the $\mathrm{Fe}(\mathrm{II}), \mathrm{Co}(\mathrm{II}), \mathrm{Ni}(\mathrm{II})$ and $\mathrm{Zn}(\mathrm{II})$ complexes of polydithiooxamide has been investigated by thermogravimetric analysis (TGA) at a heating rate of

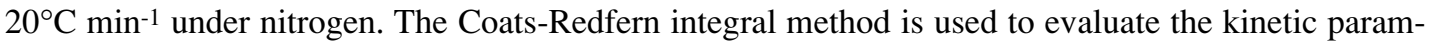
eters for the successive steps in the decomposition sequence observed in the TGA curves. The processes of thermal decomposition taking place in the four complexes are studied comparatively as the TGA curves indicate the difference in the thermal decomposition behavior of these complexes. The thermal stabilities of these complexes are discussed in terms of repulsion among electron pairs in the valence shell of the central ion and electronegativity effects.
\end{abstract}

Keywords: polydithiooxamide-complexes; thermal behaviour; kinetic parameters; thermal stability.

\section{Introduction}

The well-established thermogravimetric analysis (TGA) and differential scanning calorimetry (DSC) techniques have been reliably widely used over many decades in studying the thermal behaviour and properties of various types of materials and evaluating the thermal parameters for their degradation processes. These methods have allowed determination of the chemical steps of the investigated degradation and the evaluation, by some methods $[1,2]$, of the kinetic parameters for each step. The evaluation of the kinetic parameters has been often performed by using a single thermogravimetric curve (TG curve) recorded at a certain heating rate and atmospheres (under nitrogen or air flow).

Some recent results concerning the thermal and thermo-oxidative degradation of polymers or polymeric material, metal complexes, medicinal plant leaves and thermoplastic starch obtained by thermoanalytical methods (TG, DTG, DTA, DSC) have been reported [3 - 14]. These reports show that the kinetic parameters evaluated for each step of degradation processes are carried out by using the integral methods considering a reaction order model for the kinetic analysis of the a single thermogravimetric curve data.

In our previous studies published elsewhere [15], the temperature variation of the DC electrical conductivity was measured in the range 298 - $498 \mathrm{~K}$ for the polymer-metal complexes under investigation in the present work, and as a result the activation energies for different temperature segments were worked out. For the reason that a change in the composition may lead to changes of the measured electrical quantities (i.e. the role of adsorbed water), the thermal analysis results (TGA curves) were used only to monitor the loss of adsorbed water in order to study its effect on the DC electrical conductivity at 298 $498 \mathrm{~K}$ range. 
In this work, we illustrate a comparative study of some polymer-metal complexes of a particular ligand with various metals from the point of view of the thermogravimetric analysis (TGA) and its thermal parameters at a give condition (i.e. heating rate of $20^{\circ} \mathrm{C} \mathrm{min}-1$ under nitrogen). The chosen organic compound, dithiooxamide, is rich in electrons due to the existence of nitrogen and sulphur atoms forming the desired polydithiooxamide-metal complexes (PDTA) wherein the metal ion is placed in the backbone chain itself. In other words, the metal ion is the connecting link between the organic units in the linear chain, i.e. polymerization through coordination with the metal ion. We have chosen for the complex-ion the 3d-transition elements: $\mathrm{Fe}(\mathrm{II}), \mathrm{Co}(\mathrm{II}), \mathrm{Ni}(\mathrm{II})$ and $\mathrm{Zn}$ (II). The processes of thermal degradation taking place in these polymer-metal complexes have been investigated by thermogravimetric method (TG, DTG) and Coats-Redfern integral method [16] has been used to determine the associated kinetic parameters for the successive steps in the decomposition sequence. Although these four polymer-metal complexes are identical in terms of the ligand type around the metal ions of $\mathrm{Fe}(\mathrm{II})$, $\mathrm{Co}(\mathrm{II}), \mathrm{Ni}$ (II) and $\mathrm{Zn}$ (II), the difference in thermal decomposition behaviour and that in thermal stability are clearly observed.

Therefore, information concerning the thermal decomposition behaviour, thermal stability, mechanism and kinetics of the investigated degradation process obtained from the TG curves recorded for the four conducting polymer-metal complexes at a certain condition (i.e. heating rate of $20^{\circ} \mathrm{C} \mathrm{m^{-1 }}$ and nitrogen flow) has become of interest to be studied comparatively.

\section{Experimental} Synthesis of polymer complexes and physical
analysis

Complete details of the synthesis, physical measurements, characterization and identification as well as the DC electrical conductivity of the three conducting polymer complexes of interest (PDTA-Fe, PDTA-Co, PDTA-Ni and PDTA$\mathrm{Zn)}$ and their structure shown in structure 1 are published elsewhere [15].

\section{Thermal analysis}

The TG and DTG curves were obtained by using, Perkin-Elmer thermogravimetric Analyzer at a heating rate of $20^{\circ} \mathrm{C} \mathrm{min}{ }^{-1}$ under nitrogen flow and heating programme $30-800^{\circ} \mathrm{C}$.

\section{Methods}

From the TG and DTG curves recorded for the successive steps in the decomposition process of these polymer complexes it was possible to determine the following characteristic thermal parameters for each reaction step:

Initial point temperature of decomposition $\left(\mathrm{T}_{i}\right)$ : the point at which DTG curve starts deviating from its base line.

Final point temperature of decomposition $\left(\mathrm{T}_{f}\right)$ : the point at which DTG curve returns to its base line.

Peak temperature, i.e. temperature of maximum rate of weight loss $\left(\mathrm{T}_{D T G}\right)$ : the point obtained from the intersection of tangents to the peak of DTG curve.

Mass loss at the decomposition step $(\Delta \mathrm{m})$ : it is the amount of mass that extends from the point $\mathrm{T}_{i}$ up to the reaction end point $\mathrm{T}_{f}$ on the TG curve, i.e. the magnitude of the ordinate of a $\mathrm{TG}$ curve. The material released at each step of the decomposition is identified by attributing the mass loss $(\Delta \mathrm{m})$ at a given step to the component of similar weight calculated from the molecular formula of the investigated complexes, comparing that with literatures of relevant compounds considering their temperature. This may assist identifying the mechanism of reaction in the decomposition steps taking place in the polymer complexes under study.

Activation energy $\left(\mathrm{E}_{\mathrm{a}}\right)$ of the composition step: the integral method used is the CoatsRedfern equation [16] for reaction order $n \neq 1$, which when linearised for a correctly chosen $n$ yields the activation energy from the slop;

$$
\log \left[\frac{1-(1-\alpha)^{1-n}}{T^{2}(1-n)}\right]=\log \frac{\mathrm{ZR}}{\mathrm{qE}}\left[1-\frac{2 \mathrm{RT}}{\mathrm{E}}\right]-\frac{\mathrm{E}}{2.303 \mathrm{RT}}
$$

where: $\alpha=$ fraction of weight loss, $\mathrm{T}=$ temperature $(\mathrm{K}), \mathrm{n}=$ order of reaction, $\mathrm{Z}=$ pre-exponential factor, $\mathrm{R}=$ molar gas constant, $\mathrm{E}_{\mathrm{a}}=$ activation energy and $q=$ heating rate. 
Order of reaction (n): it is the one for which a plot of the Coats-Redfern expression gives the best straight line among various trial values of $n$ that are examined relative to that estimated by the Horovitz-Metzger method [17].

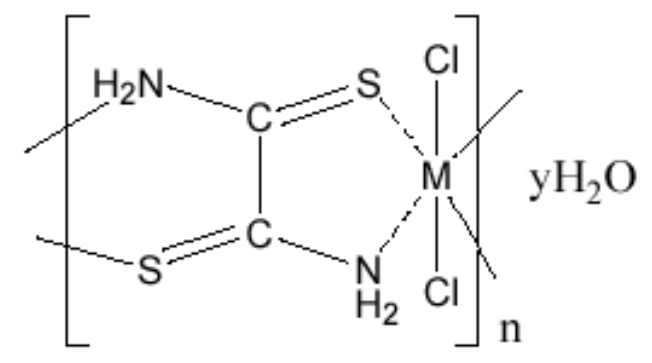

$\mathrm{M}=\mathrm{Fe}, \mathrm{Co}, \mathrm{Ni}, \mathrm{Zn}$

$\mathrm{y}=0.5,1.5,3,0$

Structure 1

\section{Results and discussion}

The thermogravimetric (TG) and derivative thermogravimetric (DTG) curves, which characterize the thermal decomposition of the $\mathrm{Fe}(\mathrm{II}), \mathrm{Co}(\mathrm{II}), \mathrm{NI}(\mathrm{II})$ and $\mathrm{Zn}$ (II) complexes of polydithiooxamide (PDTA) in nitrogen atmosphere at a heating rate of $20^{\circ} \mathrm{C} \mathrm{min}-1$ are given in Figure 1. These curves show clearly the difference in the thermal decomposition behaviour of these polymer-metal complexes and the results are summarized in Table 1. Close examination of the TG / DTG curves (Fig. 1) reveals that with overlapping steps being various, a two-step decomposition process for PDTA-Zn complex at the $132-746^{\circ} \mathrm{C}$ range, a three-step process for PDTA-Fe complex at the $30-587^{\circ} \mathrm{C}$ range, a fourstep for PDTA-Co complex at the $40-600^{\circ} \mathrm{C}$ and a five-step for PDTA-Ni complex at the 40$784^{\circ} \mathrm{C}$ range. It seems that the overlapping steps increase as the electronegativety of the metals increases; $\mathrm{Ni}>\mathrm{Co}>\mathrm{Fe}>\mathrm{Zn}$.

Table 1 compares the characteristic thermal and kinetic parameters determined or evaluated, from the TG curves, for each step in the decomposition sequence of the complexes. It can be seen clearly (Table 1) that the mass losses obtained from the TG curves and that calculated for the corre- sponding molecule or molecules are in good agreement as is the case for all of these complexes. However, as the compositions of the final decomposition products (i.e. final residues) are not proved, ill-defined final states are considered for the thermal decomposition of these four complexes. The activation energies $\left(E_{a}\right)$ are calculated from the slopes of the best fit straight lines obtained when the plots of the Coats-Redfern equation [16] are used for the best values of reaction order (n).

The first-steps of decomposition in the TG curves at the $30-140^{\circ} \mathrm{C}, 40-163^{\circ} \mathrm{C}$ and $40-190^{\circ} \mathrm{C}$ range with their temperatures of maximum rate of weight loss $\left(\mathrm{T}_{D T G}\right)$ in the DTG curves (Fig 1a,b,c) at $87^{\circ} \mathrm{C}, 88^{\circ} \mathrm{C}$ and $90^{\circ} \mathrm{C}$ indicate the loss of half molecule, one and half molecules and three molecules of water of crystallization in the $\mathrm{Fe}, \mathrm{Co}$ and Ni-polymer complexes, respectively. This corresponds well with weight loss data for $\mathrm{Fe}$ (found $3.60 \%$, cal $3.52 \%$ ), Co (found 9.68\%, cal 9.75\%) and $\mathrm{Ni}$-polymer complex (found $17.54 \%$, cal $17.79 \%$ ). Dehydration of adsorbed water is not observed in the case of $\mathrm{Zn}$ complex. The temperature ranges reported [17-19] for releasing adsorbed water in some metal complexes are in good agreement with that mentioned above. The activation energy determined for these reactions in the polymer complexes of $\mathrm{Fe}, \mathrm{Co}$ and $\mathrm{Ni}$ are 50.8 $\mathrm{kJ} \mathrm{mol}^{-1}, 48.5 \mathrm{~kJ} \mathrm{~mol}^{-1}$ and $49.1 \mathrm{~kJ} \mathrm{~mol}^{-1}$, respectively. Their temperature ranges and order of reaction (1.1, 1.7 and 2.6 for the Fe, Co and Ni complexes respectively) slightly vary (Table 1 ).

In this dehydration process, the ease of water desolvation $\left(30^{\circ} \mathrm{C} \leq \mathrm{T} \leq 190^{\circ} \mathrm{C}\right)$ in these complexes suggests that the water molecules are trapped in the crystal voids and make no contribution to the lattice forces $[20,21]$. The small differences in the $\mathrm{T}_{D T G}$ values $\left(87,88\right.$ and $90^{\circ} \mathrm{C}$ for the $\mathrm{Fe}, \mathrm{Co}$ and $\mathrm{Ni}$ complexes, respectively) and that in the values of the activation energies (50.8, 48.5 and $49.1 \mathrm{~kJ} \mathrm{~mol}^{-1}$ for $\mathrm{Fe}$, Co and $\mathrm{Ni}$ complexes, respectively) suggest that the water in these complexes may be identical, i.e., play similar little or no role in holding the crystal together.

The first-step of the PDTA-Zn complex decomposition occurs at the $132-273^{\circ} \mathrm{C}$ range (Fig 1d) with a very large and strongly sharp peak $\left(\mathrm{T}_{D T G}\right)$ at $239^{\circ} \mathrm{C}$ indicates a rapid and vigorous decomposition feature. This step is accompanied 
Table 1. Characteristic parameters of thermal decomposition $\left(20^{\circ} \mathrm{C}\right.$ min-1) for $\mathrm{Fe}(\mathrm{II}), \mathrm{Co}(\mathrm{II}), \mathrm{Ni}(\mathrm{II})$ and $\mathrm{Zn}(\mathrm{II})$ polymer complexes.

\begin{tabular}{|c|c|c|c|c|c|c|c|c|}
\hline \multirow[b]{2}{*}{ Comp. } & \multirow[b]{2}{*}{ Step } & \multicolumn{4}{|c|}{ TGA } & \multirow[b]{2}{*}{$\mathrm{n}$} & \multirow[b]{2}{*}{$\mathrm{E}_{\mathrm{a}} / \mathrm{kJ} \mathrm{mol}^{-1}$} & \multirow[b]{2}{*}{ Reaction } \\
\hline & & $\begin{array}{c}\text { Wt. Loss } \\
\text { found (calc.)\% }\end{array}$ & $\mathrm{T}_{\mathrm{i}} /{ }^{\circ} \mathrm{C}$ & $\mathrm{T}_{\mathrm{f}} /{ }^{\circ} \mathrm{C}$ & $\mathrm{T}_{\mathrm{DTG}}$ & & & \\
\hline \multirow{3}{*}{$\mathrm{Fe}$} & 1 & $3.60(3.52)$ & 30 & 140 & 87 & 1.1 & 50.8 & $-0.5 \mathrm{H}_{2} \mathrm{O}$ \\
\hline & 2 & $57.37(57.45)$ & 153 & 397 & 293 & 1.5 & 39.2 & $-\left[2 \mathrm{Cl}+63.35 \%\right.$ of $\left.\mathrm{bb}^{\mathrm{a}}\right]$ \\
\hline & 3 & $17.25(17.22)$ & 397 & 587 & 468 & 3 & 167.6 & $-[36.65 \%$ of bb] \\
\hline \multicolumn{9}{|c|}{ Final residual weight; (found $21.78 \%$, cal. $21.82 \%$ ) } \\
\hline \multirow{4}{*}{$\mathrm{Co}$} & 1 & $9.68(9.75)$ & 40 & 163 & 88 & 1.7 & 48.5 & $-1.5 \mathrm{H}_{2} \mathrm{O}$ \\
\hline & 2 & $12.84(12.80)$ & 170 & 300 & 262 & 1.3 & 90.6 & $-\mathrm{Cl}$ \\
\hline & 3 & $27.67(27.61)$ & 300 & 370 & 333 & 1.6 & 293 & $-[\mathrm{Cl}+34.14 \%$ of $\mathrm{bb}]$ \\
\hline & 4 & $15.16(15.07)$ & 370 & 600 & 533 & 2.5 & 120.4 & $-[34.74 \%$ of $b b]$ \\
\hline \multicolumn{9}{|c|}{ Final residual weight; (found $34.84 \%$, cal. $34.77 \%$ ) } \\
\hline \multirow{5}{*}{$\mathrm{Ni}$} & 1 & $17.54(17.79)$ & 40 & 190 & 90 & 2.6 & 49.1 & $-3 \mathrm{H}_{2} \mathrm{O}$ \\
\hline & 2 & $11.79(11.67)$ & 190 & 300 & 284 & 0.5 & 53.8 & $-\mathrm{Cl}$ \\
\hline & 3 & $11.64(11.67)$ & 300 & 372 & 348 & 1.2 & 206.2 & $-\mathrm{Cl}$ \\
\hline & 4 & $10.71(10.55)$ & 372 & 452 & 390 & 4 & 400.1 & $-[26.66 \%$ of bb] \\
\hline & 5 & $21.11(21.10)$ & 478 & 784 & 661 & 2 & 110.9 & $-[53.34 \%$ of bb] \\
\hline \multicolumn{9}{|c|}{ Final residual weight; (found $27.15 \%$, cal. $27.22 \%$ ) } \\
\hline \multirow[b]{2}{*}{$\mathrm{Zn}$} & 1 & $54.23(54.22)$ & 132 & 273 & 239 & 1 & 136.1 & $-[2 \mathrm{Cl}+56.71 \%$ of bb] \\
\hline & 2 & $20.38(20.29)$ & 273 & 746 & 699 & 3 & 23.4 & $-[43.29 \%$ of $\mathrm{bb}]$ \\
\hline
\end{tabular}

${ }^{\mathrm{a}} \mathrm{bb}$; Backbone components

by $54.23 \%$ weight loss recorded on the TG curve (Fig 1d) which may be accounted for by the evolution of two chloride atoms along with the decomposition of $56.71 \%$ of the backbone components (cal. $54.22 \%)$. The activation energy $\left(136.1 \mathrm{~kJ} \mathrm{~mol}^{-}\right.$ 1 ) is determined for the reaction of this step.

In the contrary, the second-step of $\mathrm{Zn}$ complex (Fig 1d) at the $273-746{ }^{\circ} \mathrm{C}$ range, with a small and weak $\mathrm{T}_{D T G}\left(699^{\circ} \mathrm{C}\right)$ due to extremely slow bleed of $20.38 \%$ weight loss, corresponds to the elimination of the remaining $43.29 \%$ of the backbone components (cal. 20.29\%). The total mass loss up to $746^{\circ} \mathrm{C}$ leaves a $25.39 \%$ residual weight, which is in agreement with the final product (cal. 25.49\%) at the end of the Zn-complex decomposition with an ill-defined final state. The activation energy $\left(23.40 \mathrm{~kJ} \mathrm{~mol}^{-1}\right)$ is determined for the reaction at this second step.

The TG curve of the PDTA-Fe complex (Fig 1a) suggests that the weight loss $(57.37 \%)$ of a rapid decomposition at the second-step (153$397^{\circ} \mathrm{C}$ ) with a very large and strong $\mathrm{T}_{D T G}$ 


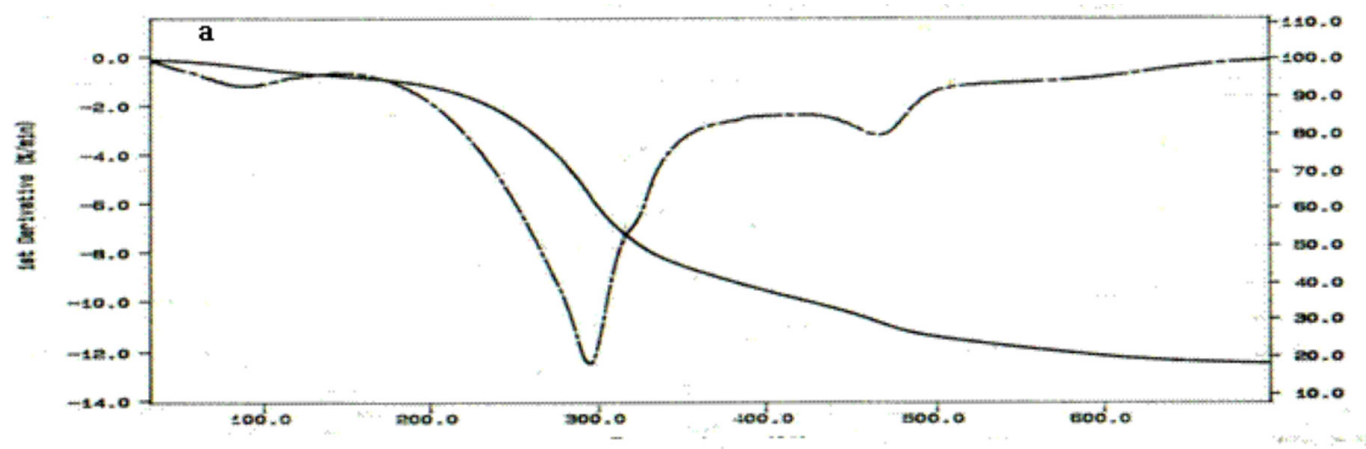

产
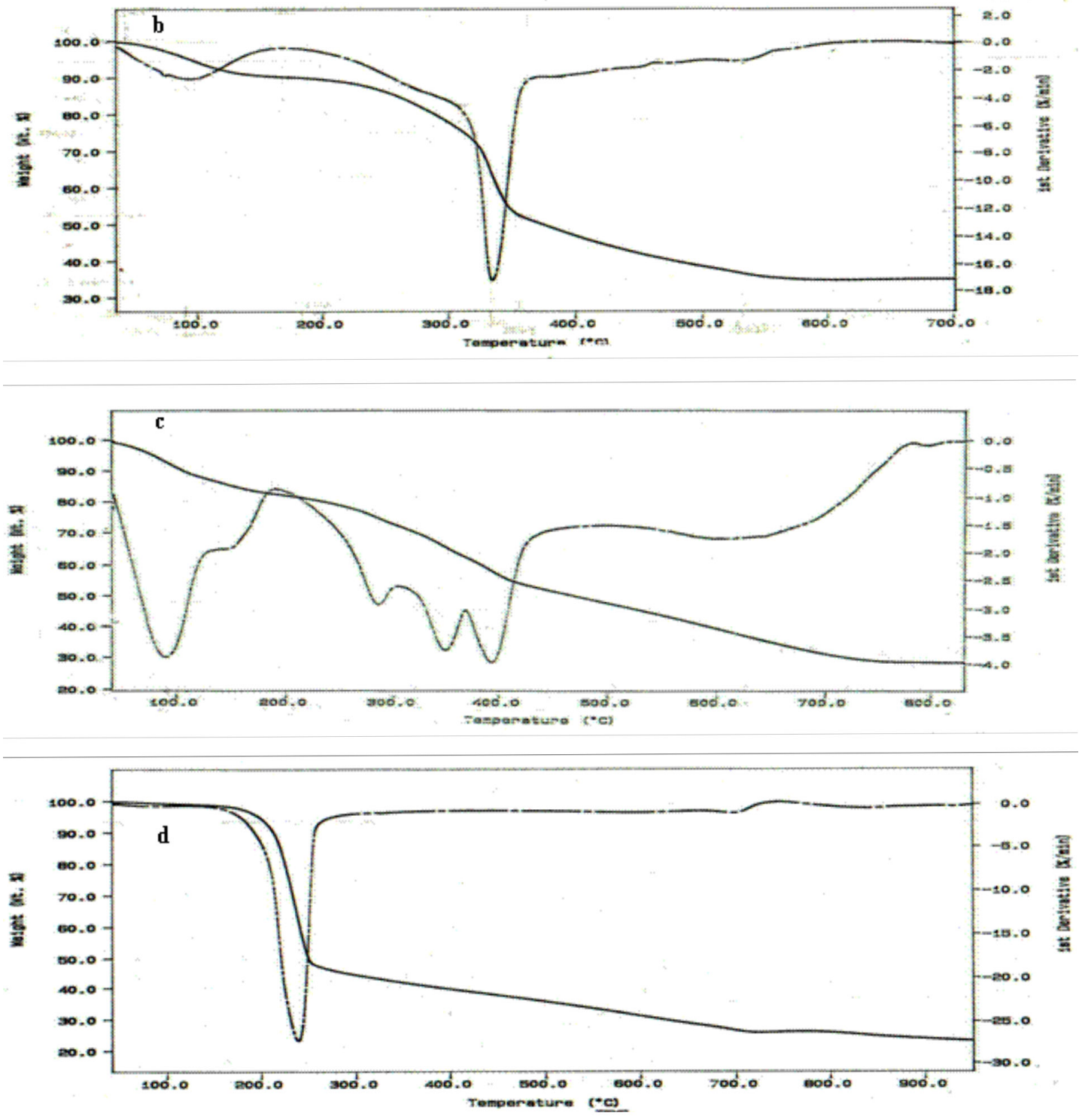

Figure 1. TGA and DTG thermograms of the PDTA complexes of Fe (a), Co (b), Ni (c) and Zn (d) in

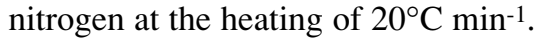


$\left(293^{\circ} \mathrm{C}\right)$, and consecutively the weight loss (17.25\%) of a gradual decomposition at the thirdstep $\left(397-587^{\circ} \mathrm{C}\right)$ with a small and broad $\mathrm{T}_{D T G}$ $\left(468^{\circ} \mathrm{C}\right)$. These correspond to the co-evolution of two chlorine atoms with $63.35 \%$ of the backbone components (cal 57.45\%) and the elimination of the remaining $36.65 \%$ of the backbone components (cal. 17.22\%), respectively. The final residual weight found $(21.78 \%)$ is referred to an illdefined final product (cal 21.82\%) at the end of the Fe-complex decomposition. The following activation energies; $39.20 \mathrm{~kJ} \mathrm{~mol}^{-1}$ and $167.60 \mathrm{~kJ}$ $\mathrm{mol}^{-1}$ are calculated for the second and third steps in the sequential decomposition of the PDTA-Fe complex, respectively.

From the TG curve of the PDTA-Co complex (Fig. 1b), four steps in the decomposition sequence are observed. The second and third steps in the $\left(170-370^{\circ} \mathrm{C}\right)$ range clearly appear as consecutive and overlapping steps. The weight loss $(12.84 \%)$ at the second-step $\left(170-300^{\circ} \mathrm{C}\right)$ with a weak and very broad peak $\left(\mathrm{T}_{D T G}\right)$ at $262^{\circ} \mathrm{C}$ suggests a very slow evolution of one chlorine atom (cal 12.80\%). This temperature range is within the acceptable limit to that reported for the release of chlorine in some complexes of cobalt $[18,20,22]$. However, the weight loss $(27.67 \%)$ at the third-step $\left(300-370^{\circ} \mathrm{C}\right)$ with a large and strongly sharp peak $\mathrm{T}_{D T G}$ at $333^{\circ} \mathrm{C}$ indicating a rapid and vigorous decomposition for the co-evolution of the second chlorine atom with $34.14 \%$ of the backbone components (cal 27.61\%). The activation energies $90.6 \mathrm{~kJ} \mathrm{~mol}^{-1}$ and $293 \mathrm{~kJ} \mathrm{~mol}^{-}$ 1 are determined for the second and third steps.

The fourth-step $\left(370-600^{\circ} \mathrm{C}\right)$ with a small and weak $\mathrm{T}_{D T G}\left(533^{\circ} \mathrm{C}\right)$ indicates that the weight loss (found $15.16 \%$, cal. $15.07 \%$ ) is due to a very slow elimination of $34.74 \%$ of the backbone components. The total mass loss up to $600^{\circ} \mathrm{C}$ is in agreement with the relative magnitude (found $34.84 \%$, cal. $34.77 \%$ ) of an ill-defined final residue of the $\mathrm{Zn}$-complex decomposition. The activation energy $\left(120.40 \mathrm{~kJ} \mathrm{~mol}^{-1}\right)$ is determined for this step.

Unlike the others, the TG curve (Fig 1c) for the Ni-complex decomposition shows five steps, with the second, third and fourth being overlapping steps at the peaks $\left(\mathrm{T}_{D T G}\right) 284^{\circ} \mathrm{C}$, $348^{\circ} \mathrm{C}$ and $390^{\circ} \mathrm{C}$, respectively. These three overlapping steps are consequent upon three rapid and consecutive decomposition processes. Therefore, the Ni-complex losses its first chlorine atom (cal. 11.67\%) at the second step (190-300 ${ }^{\circ} \mathrm{C}$ ), and the second one (cal. 11.67\%) at the third step $\left(300-372{ }^{\circ} \mathrm{C}\right)$ and then followed by the loss of $26.66 \%$ of the backbone (cal. 10.55\%) at the fourth step $\left(372-452^{\circ} \mathrm{C}\right)$. This corresponds to $11.79 \%, 11.64 \%$ and $10.71 \%$ weight losses from the TG curve (Fig. 1c) for these three consecutive and overlapping steps in the $\left(190-452^{\circ} \mathrm{C}\right)$ range, respectively. The temperatures $\left(270^{\circ} \mathrm{C}, 315^{\circ} \mathrm{C}\right.$, $220-374^{\circ} \mathrm{C}, 217-291^{\circ} \mathrm{C}$ and $330^{\circ} \mathrm{C}$ ) reported for the release of chlorine atom in some nickel complexes $[18,20,23,24]$ are in accordance with that obtained. The activation energies $\left(53.8 \mathrm{~kJ} \mathrm{~mol}^{-1}\right.$, $206.2 \mathrm{~kJ} \mathrm{~mol}^{-1}$ and $400.1 \mathrm{~kJ} \mathrm{~mol}^{-1}$ ) are determined for the second, third and fourth step reactions, respectively.

A large and a very broad peak $\left(\mathrm{T}_{D T G}\right)$ at $661^{\circ} \mathrm{C}$ for the fifth-step $\left(478-784^{\circ} \mathrm{C}\right)$ weight loss $(21.11 \%)$ is attributed to the gradual elimination of $53.34 \%$ of the backbone components (cal $21.10 \%)$. The final residual weight found $(27.15 \%)$ corresponds to an ill-defined final product (cal 27.22\%) at the end of the Ni-complex decomposition. The activation energy $(110.9 \mathrm{~kJ}$ $\mathrm{mol}^{-1}$ ) is obtained for this slow reaction at the fifth-step.

As preceded, the complex of cobalt and that of nickel both lose their two chlorine atoms in two steps. In case of nickel complex one chlorine atom in each step is observed. The secondstep of the Co-complex and of the Ni-complex assigned for the release of one chlorine atom are comparable with each other in terms of their temperature range and temperature peak $\left(\mathrm{T}_{D T G}\right)$, but their order of reaction and activation energies are incomparable. This reflects the kinetic difference and nature of these two molecules at the transition-state, i.e. their activated molecules are of different reaction nature. Therefore, rapid elimination of the chlorine atom with the lower activation energy $\left(53.8 \mathrm{~kJ} \mathrm{~mol}^{-1}\right)$ is observed in case of the Ni-complex, while in case of the Co-complex slow elimination of chlorine atom with the higher activation energy $\left(90.6 \mathrm{~kJ} \mathrm{~mol}^{-1}\right)$ is observed.

On the other hand, the thermal stability of these four polymer-metal complexes under inves- 
tigation is discussed here on the basis of the starting point (i.e. initial temperature) of the first decomposition reaction which alters the multiplebonding (six bonds) to a lower coordination numbers in the valence shells of the central ions. Hence, as the initial temperature $\left(\mathrm{T}_{\mathrm{i}}\right)$ of the decomposition peak (Table 1) is taken as a measure of the thermal stabilities of these complexes, the following may be concluded:

The nickel complex shows a higher thermal stability $\left(190^{\circ} \mathrm{C}\right)$ than those of cobalt $\left(170^{\circ} \mathrm{C}\right)$, iron $\left(153^{\circ} \mathrm{C}\right)$ and zinc $\left(132^{\circ} \mathrm{C}\right)$ and this seems to be in accordance with the increasing values of the elecronegativity in the following order $\mathrm{Ni}>\mathrm{Co}>\mathrm{Fe}>\mathrm{Zn}$ and decreasing ionic size $\mathrm{Ni}<\mathrm{Co}<\mathrm{Fe}=\mathrm{Zn}$. However, these initial temperatures $\left(190^{\circ} \mathrm{C}, 170^{\circ} \mathrm{C}, 153^{\circ} \mathrm{C}, 132^{\circ} \mathrm{C}\right.$ for the complexes of $\mathrm{Ni}, \mathrm{Co}, \mathrm{Fe}$, and $\mathrm{Zn}$, respectively) generally suggest a low thermal stability feature for these complexes. This may be due to a high repulsion among the multiple-bonding (six bonds) electron pairs in the valence shells of these complex-ions, while the small and close differences $\left(20^{\circ} \mathrm{C}, 17^{\circ} \mathrm{C}\right.$, and $21^{\circ} \mathrm{C}$; Ni-Co, Co-Fe and $\mathrm{Fe}-\mathrm{Zn}$, respectively) show no steric effect as they have only two chelate rings.

Furthermore, it is noteworthy that in the situation of lower coordination numbers where the repulsion between the electron pairs in the valence shall of the central ion is decreased, the electronegativity of the central metal seems to become the predominant factor in the stability. This is observed in the backbone decomposition of the cobalt and nickel complexes of lower coordination numbers that are produced after losing their chlorine atoms individually. As the Co-complex loses its first chlorine atom and the Ni-complex loses its two chlorine atoms, they become of lower coordination numbers as five and fourbonding electron pairs in the valence shell of the cobalt and nickel ions, respectively. In fact, the nickel of the higher electronegativity and smaller ionic size unlike the others becomes of a five and four-bonding by losing its chlorine atoms successively as degradation proceeds. Hence, if the stability of the backbone with respect to the lower coordination numbers is considered, the nickel complex shows a higher thermal stability $\left(372^{\circ} \mathrm{C}\right)$ for the initial decomposition of the backbone components, and a high thermal stability $\left(300^{\circ} \mathrm{C}\right)$ for the cobalt complex is observed. These high thermal stabilities of the nickel and cobalt complexes perhaps suggest the electronegativity as the predominant factor. However, the thermal stability difference $\left(72^{\circ} \mathrm{C}\right)$ between these two complexes explains the difference in the repulsion between the electron pairs in the five-bonding and that in the four-bonding of the cobalt and nickel complexes, respectively, i.e. higher repulsion in the five than that in the four-bonding electron pairs, and also considering the electronegativity difference between nickel and cobalt.

\section{Conclusion}

The results obtained from the TG and DTG curves (Table 1) confirm the hydration degree and the stoichiometry of the prepared PDTA metal complexes (structure 1) that are established [15] by elemental analysis ( $\mathrm{CHN}$ analyzer) and metal content measurements (Atomic absorption Spectrophotometer). In addition to that, although these polymer-metal complexes are of a particular ligand with various metals, various thermal decomposition behaviour and thermal stability are clearly observed. This may be attributed to the differences in the electronegativity values of the metals.

Recebido em: 05/12/2005

Aceito em: 08/03/2005 
H. Al-Maydama, A. El-Shekeil, M. A. Khalid and A. Al-Karbouly. Comportamento térmico da decomposição de alguns complexos metálicos de poliditiooxamidas.

Resumo: o comportamento térmico da decomposição dos complexos de poli-ditiooxamidas de Fe(II), $\mathrm{Co}(\mathrm{II}), \mathrm{Ni}(\mathrm{II})$ e $\mathrm{Zn}$ (II) foi estudado por termogravimetria (TG), com razão de aquecimento de $20^{\circ} \mathrm{C}$ $\min ^{-1}$ sob atmosfera de nitrogênio. O método integral de Coats-Redfern foi usado para calcular os parâmetros cinéticos das etapas sucessivas da decomposição observada nas curvas TGA. Os processos de decomposição térmica observados nos quatro complexos foram comparados e as suas respectivas estabilidades térmicas foram discutidas em função da repulsão entre os pares de elétrons da camada de valência do íon central e dos efeitos da eletronegatividade.

Palavras-chave: complexos de poliditiooxamidas; comportamento térmico; parâmetros cinéticos; estabilidade térmica.

\section{References}

[1] M. E. Brown, D. Dollimore and A. K. Galwey, Reactions in the solid state. Comprehensive chemical kinetics, Amsterdam: Elsevier, 1980.

[2] M. E. Brown, Introduction to Thermal Analysis. Techniques and Applications, $2^{\text {nd }}$ edition, Kluwer Academic Publishers, London, 2001.

[3] C. R. Martins, P. S. Freitas and M. A. DePaoli, Polymer Bulletin 49 (2003) 379.

[4] K. M. Kim, Y. Ouchi and Y. Chujo, Polymer Bulletin 49 (2003) 341.

[5] M. Giurginca, and T. Zaharescu, Polymer Bulletin 49 (2003) 357.

[6] J. Gonzalez, C. Albano, R. Sciamanna, M. Ichazo, C. Rosales, J. Martinez and M. Candal, Polym. Degrad. Stab. 68 (2000) 9.

[7] T. C. Chang, C. W. Yang, K. H. Wu, and Y. S. Chiu, Polym. Degrad .Stab. 68 (2000) 103.

[8] A. M. El- Naggar, A. S. Emara and S. G. Abd Alla, Polym. Degrad. Stab. 58 (1997) 79.

[9] A. S. A .Zidan, Synth React Inorg. Met-org Chem. 31(3) (2001) 457.

[10] A. A. M. Gad, Egypt J. Sol. 27(1) (2004) 89.

[11] A. Kaminska and A. Sionkowska, Polym. Degrad. Stab. 51 (1996) 15.

[12] H. Wang, et al, Polymer International 53(1) (2004) 20.
[13] M. N. Bora, Thermophysical properties of some medicinal plant leaves readily available in the north east India. Presented at the $14^{\text {th }}$ Sympoium on thermophysical properties, June 25-30, 2000, Boulder, Colorado, USA. Available from: http://www.symp14.nist.

[14] J. F. Mano, D. Koniarova and R. L. Reis, J. Materials Science: Materials in Medicine, 14 (2003) 127.

[15] A. El-Shekeil, M. A. Khalid, H. Al-Maydama and A. AlKarbooly, European Polymer Journal, 37 (2001) 575.

[16] A.W. Coats and J. P. Redfern, Kinetic parameters from thermogravimetric. Nature, 201 (1964) 68.

[17] H. H. Horovitz and G. Metzger, Anal. Chem. 35 (1963) 1464.

[18] A. M. Donia, M. M. Gouda, M. I. Ayad and H. A. ElBoraey, Thermochim Acta 194 (1992) 155.

[19] A. M. Donia, S. Abou El-Enein and M. S. Masoud, Thermochim Acta 161 (1990) 217.

[20] A. M. Donia, T. Y. Al-Ansi and M. Q. Othman, J. Thermal Anal. 50 (1997) 857.

[21] S. R .Byran, Solid statechemistry of Druge, Academic Press, New York, London, 1982.

[22] A. M. Donia. Thermochim Acta 217 (1993) 225.

[23] A. M. Donia and H. A. El-Boraey, Transition Met. Chem. 17 (1992) 305.

[24] A. M. Donia and H. A. El-Boraey, Transition Met. Chem. 18 (1993) 315. 